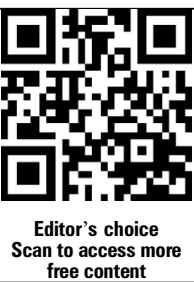

North Bristol NHS Trust, Southmead Hospital, Bristol, UK

\section{Correspondence to} Dr David Joe Unsworth, North Bristol NHS Trust, Southmead Hospital, Bristol BS10 5NB, UK; joe.unsworth@nbt.nhs.uk

Received 11 June 2013 Revised 11 September 2014 Accepted 27 November 2014

\section{SLinked}

http://dx.doi.org/10.1136/ postgradmedj-2014-133185

\section{CrossMark}

To cite: Plumb B, Bright $P$, Gompels MM, et al.

Postgrad Med J 2015:91: $3-7$.

\title{
Correct recognition and management of anaphylaxis: not much change over a decade
}

\author{
Benjamin Plumb, Philip Bright, Mark M Gompels, David Joe Unsworth
}

\begin{abstract}
Background Anaphylaxis is increasing in incidence. This potentially fatal condition requires immediate intramuscular adrenaline as a vital part of early treatment. A 2002 survey of UK Senior House Officers showed a lack of knowledge regarding the recognition and management of anaphylaxis. Since then major changes in medical education and updated national guidelines have aimed to ensure that doctors can recognise and treat anaphylaxis appropriately.

Objectives To determine current knowledge concerning the recognition and management of anaphylaxis among junior doctors compared to their predecessors.
\end{abstract}

Methods Using the same methodology as in 2002, we asked 68 Foundation doctors to read five clinical scenarios potentially suggesting anaphylaxis and indicate how they would respond to each case. Their results were compared to those of Senior House Officers in 2002.

Results 68 of 107 (64\%) junior doctors completed the questionnaire. All recognised the need for adrenaline in anaphylaxis, but only $74 \%$ selected the correct intramuscular route, and 34\% the correct route and dose. $82 \%$ of junior doctors would inappropriately give adrenaline to the patient who had inhaled a foreign body (case 2). A higher percentage of the 2013 cohort indicated the correct route and dose of adrenaline in anaphylaxis than their 2002 colleagues. However, a greater percentage also selected adrenaline treatment inappropriately in non-anaphylactic case scenarios. Conclusions Despite updated guidelines, junior doctors continue to have poor knowledge about the recognition and management of anaphylaxis, with some still considering inappropriate intravenous adrenaline. More effort should be given to the recognition of anaphylaxis in early medical training.

\section{INTRODUCTION}

Anaphylaxis is an acute, life-threatening hypersensitivity reaction that requires prompt recognition and medical treatment with intramuscular adrenaline (epinephrine). Many epidemiological studies suggest that the prevalence of anaphylaxis is increasing with a consequent rise in hospital admissions, ${ }^{1}$ although death rates from anaphylaxis do not appear to be increasing. ${ }^{2}$ Current UK estimates indicate that 1 in 1333 people will experience anaphylaxis in their lifetime.

Medical professionals such as junior doctors, who are on the front line, require knowledge about this acute, potentially fatal condition so they can accurately diagnose and appropriately treat patients in a timely manner. The National Institute of Health and Care Excellence (NICE) and the Resuscitation Council UK have recently simplified and updated guidelines for the diagnosis (figure 1) and management of anaphylaxis, specifying the dose and route of adrenaline administration. Data published by our group in this journal in $2002,{ }^{4}$ as well as other studies worldwide, ${ }^{5-8}$ have raised concerns about lack of knowledge concerning the recognition and management of anaphylaxis among front-line medical staff.

UK postgraduate medical training has seen dramatic changes to its structure and design in recent years. Since the advent of Modernising Medical Careers (MMC) in 2005, UK training has two Foundation years followed by further specialty training. Prior to 2005, medical postgraduates first undertook a pre-registration house officer (PRHO) year followed by a period of time as a senior house officer (SHO). The Foundation Programme ${ }^{9}$ was designed to equip junior doctors with a core level of knowledge and clinical skills which also allowed them to recognise and manage emergency situations such as anaphylaxis. Much of this training is now delivered through simulation and experiential learning. A requirement within Foundation training is the completion of a course such as Advance Life Support (ALS; Resuscitation Council UK), which includes the management of peri-arrest scenarios such as anaphylaxis.

In this hospital in 2002, a questionnaire-based survey was conducted of junior doctors' knowledge of anaphylaxis by our group ${ }^{4}$ and demonstrated a significant lack of knowledge surrounding the recognition and management of anaphylaxis. Our objective in undertaking this later study was to survey the current knowledge of junior doctors (Foundation trainees) regarding anaphylaxis recognition and management, and compare this to that of their historical equivalents (SHOs) of 2002, utilising the same case scenarios and the same questionnaire-based methodology.

\section{METHODS \\ Participants, the questionnaire and data collection}

The study took place at Southmead Hospital, which is a large 850-bed teaching hospital with 107 Foundation trainees. In the UK, Foundation trainees in their first year after graduation (F1s) are equivalent to the earlier PRHOs, while those in their second year of Foundation training (F2s) are more equivalent to SHOs. In mid-2013, over a 2-week period we asked Foundation trainees at Southmead Hospital to complete the same questionnaire as used in the 2002 study, to ascertain their knowledge concerning the recognition and management of anaphylaxis. The questionnaire and methodology were exactly the same as in the 2002 
Figure 1 Resuscitation Council UK working party recommendation on the management of anaphylaxis, diagnostic criteria. ${ }^{11}$

\subsection{Anaphylaxis is likely when all of the following 3 criteria are met:}

- Sudden onset and rapid progression of symptoms

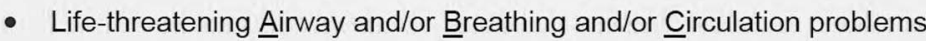

- Skin and/or mucosal changes (flushing, urticaria, angioedema)

The following supports the diagnosis:

- Exposure to a known allergen for the patient

Remember:

- Skin or mucosal changes alone are not a sign of an anaphylactic reaction

- Skin and mucosal changes can be subtle or absent in up to $20 \%$ of reactions (some patients can have only a decrease in blood pressure, i.e., a $\underline{\text { Circulation problem) }}$

- There can also be gastrointestinal symptoms (e.g. vomiting, abdominal pain, incontinence) study ${ }^{4}$ and used five clinical scenarios describing patients with symptoms that have some or all of the features of anaphylaxis (box 1).

\section{Box 1 Case scenarios}

1. A 55-year-old woman is admitted by ambulance with a widespread, raised erythematous rash immediately after eating shellfish. She is acutely dyspnoeic, wheezing and hoarse. She is conscious. Intravenous access is established. Her pulse is $110 \mathrm{bpm}$, blood pressure $80 / 60 \mathrm{~mm} \mathrm{Hg}$, respiratory rate $28 / \mathrm{min}$, oxygen saturations $90 \%$ on oxygen.

2. A 32-year-old man presents with dyspnoea $15 \mathrm{~min}$ after eating two packets of dry salted peanuts. He doesn't have a rash. He has difficulty talking and complains that his throat feels swollen. He has inspiratory stridor but no wheeze. His pulse is $90 \mathrm{bpm}$, blood pressure $145 / 78 \mathrm{~mm} \mathrm{Hg}$, respiratory rate $24 / \mathrm{min}$, oxygen saturations $98 \%$ on air.

3. A 30-year-old man has a widespread, pruritic, raised erythematous rash developing over $45 \mathrm{~min}$. He carries an EpiPen (Meridian Medical Technologies, Columbia, Maryland, USA) prescribed by his general practitioner for previous similar occurrences and has used this before arrival. He has no wheeze. His pulse is $110 \mathrm{bpm}$, blood pressure $158 / 96 \mathrm{~mm} \mathrm{Hg}$, respiratory rate 18/min, oxygen saturations $100 \%$ on air.

4. A 26-year-old woman has a widespread, erythematous rash and pruritis 1 day after starting a course of penicillin for an upper respiratory tract infection. She has a history of asthma and of a previous rash with antibiotics but doesn't know which. Her pulse is $104 \mathrm{bpm}$, blood pressure $97 / 55 \mathrm{~mm} \mathrm{Hg}$, respiratory rate $16 / \mathrm{min}$, oxygen saturations $98 \%$ on air, peak flow rate $80 \%$ of that predicted.

5. A 74-year-old man has a grossly swollen lower lip and tongue swelling developing over the last $45 \mathrm{~min}$. His history includes ischaemic heart disease and hypertension. He has difficulty talking because of the tongue. He has no audible stridor or wheeze. His pulse is $84 \mathrm{bpm}$, blood pressure $168 / 95 \mathrm{~mm} \mathrm{Hg}$, respiratory rate $18 / \mathrm{min}$, oxygen saturations $97 \%$ on air.
The scenario in case 1 is a typical case of true anaphylaxis requiring emergency adrenaline $(0.5 \mathrm{~mL}$ of $1: 1000$ intramuscular, $500 \mu \mathrm{g})$. Cases 2-5 are not suggestive of anaphylaxis and therefore should not be treated with adrenaline; indeed it may be potentially harmful in some cases to do so (eg, elderly patients with arteriopathy) in the absence of anaphylaxis. ${ }^{10}$ The recently updated Resuscitation Council UK guideline ${ }^{11}$ for identifying anaphylaxis provides a summary of diagnostic criteria for anaphylaxis (figure 1), and these underpin the 'correct' answers.

The questionnaire was given to Foundation trainees when they attended routine curriculum teaching sessions. Trainees were informed that the questionnaire aimed to assess their knowledge of anaphylaxis, would be assessed anonymously, and that the results were intended for publication. They were asked to complete the questionnaire without conferring, within $5 \mathrm{~min}$ and without reference materials. Participants were asked to mark an answer grid showing alternative responses (table 1) with an appropriate drug treatment (if any) for each case and, where appropriate, were required to specify the dose/route of adrenaline administration (intravenous bolus, slow intravenous infusion, subcutaneous injection, intramuscular injection or nebulised). Dose options included: $10 \mathrm{~mL}$ of $1: 10000,1 \mathrm{~mL}$ of $1: 10000,1 \mathrm{~mL}$ of $1: 1000,0.5 \mathrm{~mL}$ of $1: 1000$ and $0.3 \mathrm{~mL}$ of $1: 1000$. There was a further option of 'None' if they thought adrenaline was not appropriate.

Table 1 Answer grid: for each of the cases, please mark with an $\mathrm{X}$ an appropriate combination of dose and route for adrenaline (if any) which you would administer

\begin{tabular}{|c|c|c|c|c|c|}
\hline Adrenaline & Bolus IV & Slow IV & IM & Sub cut & Nebulised \\
\hline \multicolumn{6}{|c|}{$10 \mathrm{~mL}$ 1:10 000} \\
\hline \multicolumn{6}{|c|}{$1 \mathrm{~mL} \mathrm{1:10000}$} \\
\hline \multicolumn{6}{|l|}{$1 \mathrm{~mL} 1: 1000$} \\
\hline \multicolumn{6}{|c|}{$0.5 \mathrm{~mL} 1: 1000$} \\
\hline \multicolumn{6}{|c|}{$0.3 \mathrm{~mL} 1: 1000$} \\
\hline \multicolumn{6}{|l|}{ None } \\
\hline \multicolumn{6}{|c|}{$\begin{array}{l}\text { Participants were also asked for the following personal information: stage of training } \\
\text { (Foundation Year } 1 \text { or 2), whether they had previously worked in an emergency } \\
\text { department, and whether they had completed the advanced life support course or } \\
\text { equivalent. 'Correct' answers were not available to trainees until after the study had } \\
\text { been completed and data analysed. }\end{array}$} \\
\hline
\end{tabular}




\section{Data analysis and statistics}

Data were initially compiled using MS Excel. Statistical comparisons of similar data sets from 2002 and 2013 were carried out using web-based calculators available at http://www.graphpad. com. Two-by-two contingency tables were produced comparing numbers or trainees who would and would not give a treatment for the 2002 and 2013 cohorts. Where presented, p values demonstrate the difference between the cohorts and are calculated using a two-tailed Fisher's exact test.

\section{Ethics}

Ethics committee approval was deemed unnecessary, as the survey was an evaluation of current practice using nonidentifiable case scenarios. Completion of the questionnaire implied consent for this process.

\section{RESULTS}

In total, 68/107 (64\%) Foundation year trainees based at Southmead Hospital completed the questionnaire, of whom exactly half (34) were Foundation Year 1 (F1) and half (34) were Foundation Year 2 (F2) doctors. None of the F1s had undertaken advanced life support (ALS) training or had worked in an emergency department (ED). Of the F2s, 33/34 (97\%) had completed the ALS course and 4/34 (12\%) had worked in an ED. The 2002 cohort were all SHOs, and therefore were likely to be $1-3$ years more senior than their 2013 Foundation year equivalents. It is unknown how many of the 2002 cohort had undertaken ALS or had worked in an ED previously. Results from our 2013 survey together with comparative results from 2002 are shown in table 2.

Case 1 (true anaphylaxis) received adrenaline from $100 \%$ of participants. Twenty-three of the 68 (34\%) administered the correct dose by the correct route $(0.5 \mathrm{~mL}$ of $1: 1000$, intramuscular), 27/68 (40\%) chose the correct route (intramuscular) but an incorrect dose, 17/68 (25\%) dangerously chose the intravenous route and 1/68 (1\%) incorrectly chose either subcutaneous or nebulised routes of administration.

Case 2 (inhaled foreign body) received adrenaline from 56/68 (82\%), delivered intramuscularly by $43 / 68$ (63\%), intravenously by $3 / 68(4 \%)$ and nebulised by $1 / 68(1 \%)$.

Case 3 (benign urticaria) received adrenaline from 14/68 $(21 \%)$, delivered intramuscularly by $8 / 68(12 \%)$, intravenously by $4 / 68(6 \%)$ and subcutaneously by one trainee $(1 \%)$.
Case 4 (rash with antibiotics and asthma) received adrenaline from $15 / 68(22 \%)$, delivered intramuscularly by $9 / 68(13 \%)$, intravenously by $2 / 68(3 \%)$ and via alternative routes by $2 / 68(3 \%)$.

Case 5 (angioedema) was (ignoring case 1) arguably the next closest presentation to anaphylaxis but clearly lacked any evidence of airway, breathing or circulatory collapse and the patient had risk factors for adrenaline administration (ischaemic heart disease). Here, 47/68 (69\%) chose to administer adrenaline, 36/68 (53\%) intramuscularly and 7/68 (10\%) dangerously selecting the intravenous route.

\section{Comparison of F1s with F2s}

For case 1 (true anaphylaxis), all F1s and F2s chose to administer adrenaline, but more F2s $(27 / 34,79 \%)$ chose the correct route than their F1 $(23 / 34,68 \%)$ counterparts (see figure 2), but this difference was not statistically significant $(p=0.41)$. Thirty-three out of 34 F2s and 0/34 F1s had passed their ALS, meaning that passing the ALS is confounded by the increased experience and seniority of being an F2 compared to an F1. Only 4/68 (6\%) of the surveyed doctors had worked in an ED, making statistical comparison of those who had and had not worked in an ED very difficult. Statistical comparison of those who have/have not passed ALS or worked/not worked in an ED will not be discussed further in this article.

\section{Comparison of the 2013 with the 2002 cohort}

In 2002 , only $35 / 78$ (45\%) trainees were able to correctly identify the correct route of adrenaline administration in case scenario 1 (true anaphylaxis) compared to $50 / 68(74 \%)$ in 2013, which is a statistically significant improvement $(\mathrm{p}=0.0007)$ (see table 2). Only $10 / 78$ (13\%) of the 2002 cohort were able to correctly identify both dose and administration route for case scenario 1 , compared with $23 / 68$ (34\%) in 2013, which is also a statistically significant improvement $(p=0.0029)$. For case 1 , inappropriate intravenous adrenaline would have been given by $33 / 78(42 \%)$ in 2002 compared to $17 / 68(25 \%)$ in 2013 , which is again a statistically significant improvement $(p=0.0359)$.

Inappropriate adrenaline administration (all routes) was selected more frequently in non-anaphylactic presentations (cases 2-5) in 2013 compared to 2002. In 2013, 132/272 (49\%) respondents would have administered adrenaline for nonanaphylactic presentations compared to 101/312 (32\%) respondents in 2002, which is a statistically significant deterioration $(\mathrm{p}<0.0001)$

Table 2 Junior doctor results in $2013(n=68)$ compared with $2002(n=78)$

\begin{tabular}{|c|c|c|c|c|c|c|c|}
\hline Case no. & Actual diagnosis & Year & $\begin{array}{l}\text { Adrenaline given (all } \\
\text { routes and all } \\
\text { doses) }\end{array}$ & $\begin{array}{l}\text { IM adrenaline } \\
\text { (any dose) }\end{array}$ & $\begin{array}{l}\text { IM adrenaline } 0.5 \mathrm{mg} \\
1: 1000 \text { (correct route } \\
\text { and dose) }\end{array}$ & $\begin{array}{l}\text { IV adrenaline } \\
\text { (any dose) }\end{array}$ & $\begin{array}{l}\text { Other, for example, } \\
\text { subcut/nebulised adrenaline } \\
\text { (any dose) }\end{array}$ \\
\hline 1 & Anaphylaxis & $\begin{array}{l}2013 \\
2002\end{array}$ & $\begin{array}{l}68(100) \\
78(100)\end{array}$ & $\begin{array}{l}50(74) \\
35(45)\end{array}$ & $\begin{array}{l}23(34) \\
10(13)\end{array}$ & $\begin{array}{l}17(25) \\
33(42)\end{array}$ & $\begin{array}{l}1(1) \\
6(8)\end{array}$ \\
\hline 2 & $\begin{array}{l}\text { Foreign body } \\
\text { inhalation }\end{array}$ & $\begin{array}{l}2013 \\
2002\end{array}$ & $\begin{array}{l}56(82) \\
44(56)\end{array}$ & $\begin{array}{l}43(63) \\
23(29)\end{array}$ & $\begin{array}{c}17(25) \\
6(8)\end{array}$ & $\begin{array}{c}3(4) \\
13(17)\end{array}$ & $\begin{array}{l}1(1) \\
3(4)\end{array}$ \\
\hline 3 & Urticaria & $\begin{array}{l}2013 \\
2002\end{array}$ & $\begin{array}{r}14(21) \\
8(10)\end{array}$ & $\begin{array}{l}8(12) \\
3(4)\end{array}$ & $\begin{array}{l}2(3) \\
3(4)\end{array}$ & $\begin{array}{l}4(6) \\
1(1)\end{array}$ & $\begin{array}{l}1(1) \\
2(3)\end{array}$ \\
\hline 4 & $\begin{array}{l}\text { Rash, ? antibiotic } \\
\text { related, mild asthma }\end{array}$ & $\begin{array}{l}2013 \\
2002\end{array}$ & $\begin{array}{l}15(22) \\
17(22)\end{array}$ & $\begin{array}{l}9(13) \\
6(8)\end{array}$ & $\begin{array}{l}4(6) \\
5(6)\end{array}$ & $\begin{array}{l}2(3) \\
5(6)\end{array}$ & $\begin{array}{l}2(3) \\
2(3)\end{array}$ \\
\hline 5 & $\begin{array}{l}\text { Angioedema (with } \\
\text { ischaemic heart } \\
\text { disease) }\end{array}$ & $\begin{array}{l}2013 \\
2002\end{array}$ & $\begin{array}{l}47(69) \\
32(41)\end{array}$ & $\begin{array}{l}36(53) \\
17(22)\end{array}$ & $\begin{array}{c}12(18) \\
6(8)\end{array}$ & $\begin{array}{l}7(10) \\
7(9)\end{array}$ & $\begin{array}{l}1(1) \\
5(8)\end{array}$ \\
\hline
\end{tabular}


Figure 2 Comparison of treatment choices of Foundation Year 1 (F1s) versus Foundation Year 2 (F2s) trainees intramuscular; IV, intravenous; neb, nebulised; s/c, subcutaneous. in 2013, for anaphylaxis (case 1). IM,

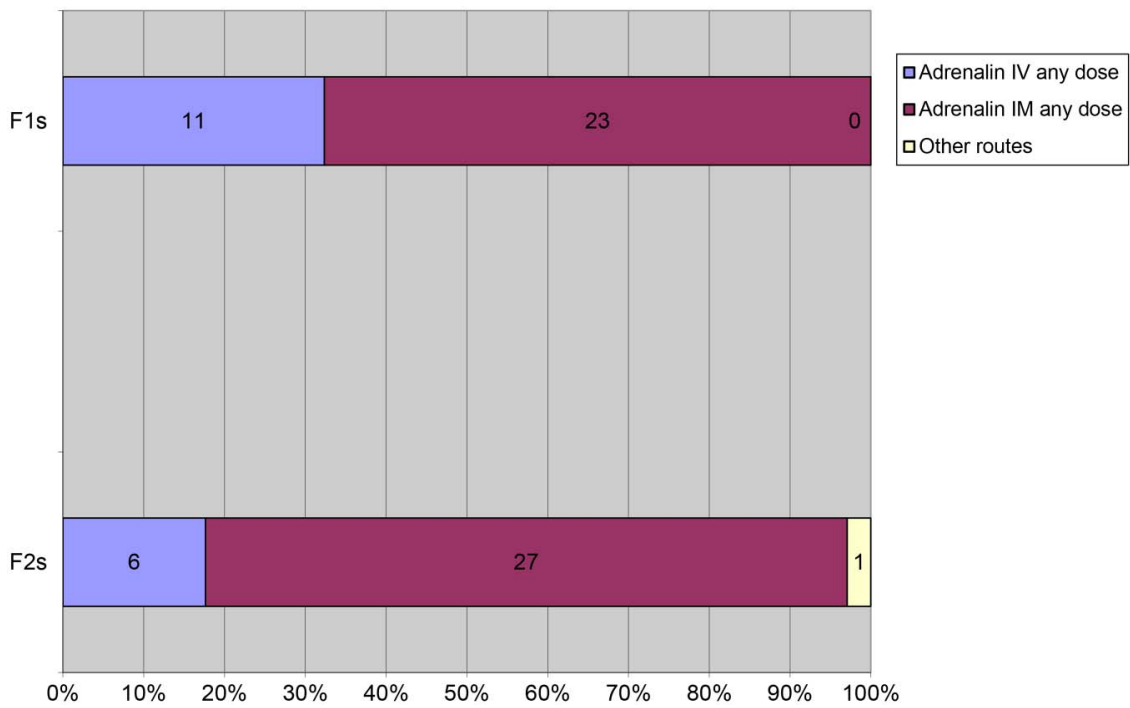

\section{DISCUSSION}

The results demonstrate that junior doctors still have significant knowledge gaps relating to both the recognition and management of anaphylaxis. The need for adrenaline treatment was recognised by all the junior doctors in the case of true anaphylaxis, but the proportion of trainees who are aware of the correct dose and route of administration is still unacceptably low $(34 \%)$. A worryingly high proportion of trainees $(25 \%)$ suggested inappropriate intravenous administration of adrenaline, which is high risk and associated with iatrogenic deaths. ${ }^{2}$ Our results also demonstrate a lack of understanding regarding the recognition of allergic conditions and the diagnosis of anaphylaxis. Overall, $49 \%$ of all responses in non-anaphylactic presentations (cases 2-5) in our 2013 survey indicated administration of adrenaline for conditions other than anaphylaxis, strongly suggesting more training and education is required in this area.

There are few published data directly comparing similar groups of trainees' responses to emergency scenarios before and after the introduction of the $2005 \mathrm{MMC}$ changes in medical education.

Our study obtained results from trainees in both Foundation years. Foundation Year 2 trainees were found to have a slightly higher, but statistically insignificant, correct response rate regarding dose and route of adrenaline in true anaphylaxis when compared with more junior F1 trainees.

Our 2013 and 2002 surveys compared trainee doctors from two different training eras with similar levels of experience, within the same hospital, using the same methodology. Limitations of this study include the fact that it was based in a single centre, and that it only sampled a proportion (64\%) of the Foundation cohort. While weekly teaching provided an ideal opportunity to enlist trainees, ward responsibilities and rota patterns limited the availability of participants on a random basis. There is a potential discrepancy in the level of experience among trainees in the 2002 and 2013 cohorts, which could have affected results. The 2002 survey incorporated responses from trainees who, due to training at the time, may have been 3 or 4 years post-graduation ('SHOs') and therefore were perhaps more experienced at managing emergency situations. However, our current results still show a worrying knowledge gap in front-line hospital trainee doctors. A potential bias may have been introduced into any comparison between the 2013 and the 2002 survey by the ALS course as we are unsure what proportion of 2002 survey participants had completed this training.

In conclusion, junior doctors in training in 2013 were still unable to accurately distinguish anaphylaxis from other similar presentations, only a small proportion were aware of the correct dose and route of adrenaline for emergency management, and too many would seriously consider the intravenous route. Incorrect use of adrenaline as a treatment for a number of allergic or similar conditions, where administration is inappropriate and may prove dangerous, is another concern.

Remedial action to improve knowledge regarding the recognition and management of anaphylaxis needs to be provided through Foundation Programme training and at medical school. Currently, there is no specific anaphylaxis or allergy teaching outside of the ALS course at this level. Interestingly, this was also a finding in 2002 where it was noted that 'guidelines are of use only if the diagnosis is correct. Our cohort had not received formal teaching on anaphylaxis management and we suggest that improved training in this area is required'. We would echo the recommendations of the Resuscitation Council UK Anaphylaxis Working Group who suggest that "clinical staff who give parenteral medications should have initial training and regular updates in dealing with anaphylactic reactions'. ${ }^{11}$ The Foundation Programme provides an ideal opportunity to equip junior trainees with a sound understanding of emergency management. With increasing use of simulation in training, we would suggest that anaphylaxis and allergic-like conditions are a high priority for training and education among this cohort.

\section{Main messages}

- There is still a significant lack of knowledge among junior doctors about recognising and managing anaphylaxis, including how to administer adrenaline.

- In keeping with national guidance, all junior doctors should be taught to identify and treat life-threatening anaphylaxis, and be assessed to ensure that they have acquired this expertise. 


\section{Current research questions}

- Would more focused training on identifying and diagnosing anaphylaxis cases improve results?

- In a more clinical setting, such as a simulated environment, are actions different to survey responses?

\section{Key references}

- Pumphrey RS. Lessons for management of anaphylaxis from a study of fatal reactions. Clin Exp Allergy 2000;30:1144-50.

- National Institute for Health and Care Excellence. Anaphylaxis: Assessment to confirm an anaphylactic episode and the decision to refer after emergency treatment for a suspected anaphylactic episode. http://www.nice.org.uk/ guidance/CG134 (accessed 19 Jul 2014).

- Resuscitation Council UK, Advanced Life Support Course website. http://www.resus.org.uk/pages/reaction.htm (accessed 19 Jul 2014).

Contributors BP designed the project, collected and interpreted the data, and wrote the article. PB collaborated in study design, data interpretation and writing the article. MMG designed the original study, case reports and data collection tool and was involved in writing the article. DJU designed the project and data collection tool and took part in data interpretation and in writing the article. All authors have approved the final article for submission.
Competing interests BP is also an ALS instructor and DJU was part of the working group which produced the Resuscitation Council UK guidelines.

Provenance and peer review Not commissioned; externally peer reviewed.

Data sharing statement All data are the property of North Bristol NHS Trust and are shared freely and openly.

\section{REFERENCES}

1 Department of Health. A review of services for allergy. The epidemiology, demand for, and provision of treatment and effectiveness of clinical interventions. Department of Health, 2006.

2 Pumphrey RS. Lessons for management of anaphylaxis from a study of fatal reactions. Clin Exp Allergy 2000;30:1144-50.

3 National Institute for Health and Care Excellence. Anaphylaxis: Assessment to confirm an anaphylactic episode and the decision to refer after emergency treatment for a suspected anaphylactic episode. http://www.nice.org.uk/guidance/CG134 (accessed 19 Jul 2014).

4 Gompels LL, Bethune C, Johnston SL, et al. Proposed use of adrenaline (epinephrine) in anaphylaxis and related conditions: a study of senior house officers starting accident and emergency posts. Postgrad Med J 2002;78:416-18.

5 Adiga S, Nayak V, Bairy K. Treatment of anaphylaxis in adults: a questionnaire survey. Online J Health Allied Sci 2008;7:6.

6 Jose R, Clesham GJ. Survey of the use of epinephrine (adrenaline) for anaphylaxis by junior hospital doctors. Postgrad Med J 2007;83:610-11.

7 Droste J, Narayan N. Anaphylaxis: lack of hospital doctors' knowledge of adrenaline (epinephrine) administration in adults could endanger patients' safety. Eur Ann Allergy Clin Immunol 2012;44:122-7.

8 Thain S, Rubython J. Treatment of anaphylaxis in adults: results of a survey of doctors at Dunedin Hospital, New Zealand. N Z Med J 2007;120:U2492.

9 Foundation Programme Curriculum. The UK foundation programme curriculum. Academy of Medical Royal Colleges Foundation Programme Committee, 2012.

10 Johnston SL, Unsworth J, Gompels MM. Adrenaline given outside the context of life threatening allergic reactions. BMJ 2003;326:589-90.

11 Resuscitation Council UK, Advanced Life Support Course website. http://www.resus. org.uk/pages/reaction.htm (accessed 19 Jul 2014) 